\title{
Production of Pycnidia and Conidia by Guignardia bidwellii, the Causal Agent of Grape Black Rot, as Affected by Temperature and Humidity
}

\author{
G. Onesti, E. González-Domínguez, and V. Rossi
}

Department of Sustainable Crop Production, Università Cattolica del Sacro Cuore, Via E. Parmense 84, Piacenza, I-29122, Italy. Accepted for publication 29 September 2016.

\begin{abstract}
Black rot, caused by the fungus Guignardia bidwellii, is a polycyclic disease affecting grape leaves and berries. In environmentally controlled experiments and in a 3-year field study, the effects of temperature and relative humidity $(\mathrm{RH})$ were assessed on the following growth parameters of G. bidwellii: (i) formation of pycnidia and cirri in grape leaf lesions, (ii) production and germination of conidia, and (iii) length of the period between lesion appearance and pycnidia production. Pycnidia were produced between 5 and $35^{\circ} \mathrm{C}$ and at 90 to $100 \% \mathrm{RH}$ but more pycnidia were produced between 20 and $30^{\circ} \mathrm{C}$. No pycnidia were produced at $\mathrm{RH}<$ $90 \%$. The first pycnidia were produced in approximately 2 days after lesion appearance at $\geq 20^{\circ} \mathrm{C}$ and in 8 days at $5^{\circ} \mathrm{C}$; pycnidia continued to be

produced on the same lesion for 5 to 16 days after lesion appearance, depending on the temperature. Models were developed to describe the effect of temperature and $\mathrm{RH}$ on pycnidia production, accounting for 95 and $97 \%$ of variability, respectively. Cirri were extruded only between 15 and $35^{\circ} \mathrm{C}$ and mainly at $100 \% \mathrm{RH}$. Field experiments confirmed that pycnidia are produced for several days on a leaf lesion and that the length of the period between lesion appearance and pycnidia production depends on temperature. Overall, the findings showed that production of conidia requires high humidity; under field conditions, some hours at high humidity, which usually occur at nighttime, rather than constant high humidity may be sufficient.
\end{abstract}

Black rot of grape, caused by the ascomycete Guignardia bidwellii (Ellis) Viala \& Ravaz (anamorph: Phyllosticta ampelicida (Englem.) Aa), can cause crop losses between 5 and $80 \%$ (in severely affected vineyards, even $100 \%$ ) and can also reduce wine quality, especially in grape-growing areas with a cold and humid spring and early summer (Ellis et al. 1986; Ferrin and Ramsdell 1977, 1978; Magarey et al. 1993; Molitor and Beyer 2014; Ramsdell and Milholland 1988; Rinaldi et al. 2013).

G. bidwellii overwinters in mummified berries on the soil surface and on vines, and in cane lesions as pycnidia (Ramsdell and Milholland 1988). During the following grape-growing season, the fungus produces both ascospores and conidia on these inoculum sources (Hoffman et al. 2004). Both spore types are repeatedly dispersed and cause primary infections on leaves and on all other green tissues (Ferrin and Ramsdell 1977). After incubation (Molitor et al. 2012), typical black rot lesions appear on leaves as light-brown necrotic circles that later develop a narrow border of dark-brown tissue (Kuo and Hoch 1996; Ramsdell and Milholland 1988). After 1 to 5 additional days, pycnidia form on these lesions as small, black protuberances (Ramsdell and Milholland 1988; Spotts 1980). On shoots, tendrils, and petioles, the lesions are elongate and have pycnidia in their centers (Northover 2008). In the presence of free water, mature pycnidia extrude conidia in a mucilaginous exudate, the cirrus (Janex-Favre et al. 1993). These conidia are dispersed by rain and cause secondary infections that contribute to the disease development during the growing season (Ferrin and Ramsdell 1978). G. bidwellii also causes berry rot (Ramsdell and Milholland 1988; Reddick 1911). Rotted berries progressively turn into hard, blue-black mummies at the end of the season (Kuo and Hoch 1996; Molitor and Beyer 2014; Reddick 1911; Sosnowski et al. 2012).

The effect of environmental conditions on the incubation period has been previously studied (Hoffman et al. 2002; Molitor et al. 2012)

Corresponding author: V. Rossi; E-mail address: vittorio.rossi@unicatt.it

(c) 2017 The American Phytopathological Society but there is little information on how environmental conditions affect the duration of the period elapsing between the appearance of lesions and the formation of pycnidia, the production of pycnidia and conidia, and the formation of cirri (Rossi et al. 2014). Spotts (1980) evaluated the effect of three temperatures $\left(15,21\right.$, and $\left.26^{\circ} \mathrm{C}\right)$ and three relative humidity $(\mathrm{RH})$ levels $(50,70$, and $90 \%)$ on the production of pycnidia after $16 \mathrm{~h}$ of incubation. Caltrider (1961) and Viala and Pacottet (1904) evaluated the production of G. bidwellii pycnidia at different temperatures on artificial media but not on grape tissue. None of the previous work considered the production and extrusion of conidia. Northover (2008) studied the production of G. bidwellii pycnidia on shoot lesions as affected by temperature and wetness duration at the time of infection but he did not consider the effect of environmental factors on the time required for pycnidia to develop.

In other fungi that produce pycnidia, such as Didymella rabiei (Jhorar et al. 1998), Phomopsis amygdale (Lalancette et al. 2003), and P. viticola (Anco et al. 2013), the production of pycnidia and conidia is affected by temperature and humidity. The time required for the production of pycnidia is also influenced by temperature and humidity for Leptosphaeria maculans (Vanniasingham and Gilligan 1989) and Septoria tritici (Shaw 1990; Shearer and Zadoks 1972).

The objective of this article was to assess the effects of temperature and humidity on (i) the formation of G. bidwellii pycnidia and cirri in grape leaf lesions, (ii) the production and germination of conidia, and (iii) the length of the period from lesion appearance to pycnidia production. Studies were conducted with grape leaves under environmentally controlled conditions and in a vineyard in northern Italy.

\section{MATERIALS AND METHODS}

In vitro experiments. Fungal material. The strain of G. bidwellii used, G1.16,was provided by Prof. L. Mugnai, Università degli Studi di Firenze (Italy); G1.16 was isolated from a severely affected vineyard of 'Colorino' grape located in Quarrata (Tuscany, Italy). 
The strain was maintained at $5^{\circ} \mathrm{C}$ in glass tubes $(5 \mathrm{ml})$ containing water agar (WA) (20 $\mathrm{g} \mathrm{liter}^{-1}$; HIMEDIA, Mumbai, India). For the production of conidia used for artificial inoculations, a small plug of the colonized WA was transferred from the glass tubes to petri plates containing malt extract agar (50 $\mathrm{g}$ liter $^{-1}$; HIMEDIA), and plates were incubated for 3 weeks at $25^{\circ} \mathrm{C}$ with a 12-h photoperiod. Conidial suspensions were obtained by flooding the plates with $10 \mathrm{ml}$ of sterile distilled water and gently scrapping the agar surface with a sterile spatula. The resulting suspension was filtered through a double layer of gauze and was adjusted to $10^{4}$ conidia $\mathrm{ml}^{-1}$ with the aid of a hemocytometer.

Plant material and artificial inoculations. One-year-old Vitis vinifera 'Barbera' plants, which are susceptible to G. bidwellii (Rubboli et al. 2014), were grown in a greenhouse at the University of Piacenza campus (Italy). The plants were rooted in plastic pots $(10 \mathrm{~cm}$ in diameter) containing a mixture of sand, peat moss, and soil (20:50:30), and were grown at a temperature ranging from 18 to $26^{\circ} \mathrm{C}$ with a 12 -h photoperiod (the natural light was supplemented with light provided by Philips Master Tl-D 90 Deluxe 18 W/950 lamps) until they had shoots with four to six unfolded leaves. Shoots were positioned vertically, and the adaxial surface of the second, third, and fourth unfolded leaves from the shoot apex were inoculated with10- $\mu$ l drops ( 3 to 5 drops/leaf) of the conidial suspension, prepared as described above. After inoculation, the plants were covered with transparent plastic bags to ensure a saturated atmosphere and were incubated at $25^{\circ} \mathrm{C}$ with a 12 -h photoperiod to facilitate infection. Plastic bags were removed after $48 \mathrm{~h}$, and the plants were kept at $25^{\circ} \mathrm{C}$ with 12 -h photoperiod and with 50 to $60 \%$ RH until typical black rot lesions appeared. Plants were checked daily and first lesions appeared after approximately 12 days, at which time they had yet to produce pycnidia.

Fourteen days after inoculation, segments were cut from the leaves such that each segment had a single lesion. Leaf segments were disinfested with sodium hypochlorite $(2 \%)$ for $2 \mathrm{~min}$, rinsed with sterile water, and finally dried in a laminar flow cabinet. To prevent curling, the leaf segment was laid on a piece of sterile plastic net and was then covered with another piece of net that was fixed to the lower piece with sterile clips; the upper piece of net had a hole that was slightly larger than the lesion.

Effect of $\mathrm{RH}$ and temperature. To study the effect of $\mathrm{RH}$ and temperature on the development of pycnidia and on the extrusion of cirri, leaf segments prepared as described in the previous section were placed in petri dishes (one leaf segment per dish) containing potato dextrose agar (PDA) (39 $\mathrm{g} \mathrm{liter}^{-1}$; HIMEDIA) amended with streptomycin sulfate ( $0.1 \mathrm{~g}^{\text {liter }}{ }^{-1}$; Sigma-Aldrich, St. Louis). The dishes were kept in incubators at (i) $25^{\circ} \mathrm{C}$ with a 12 -h photoperiod and $65,80,90,95$, or $100 \% \mathrm{RH}$ (experiment 1 ); or (ii) $5,10,15,20$, $25,30,35$, or $40^{\circ} \mathrm{C}$ with a 12 -h photoperiod and $100 \% \mathrm{RH}$ (experiment 2). The interaction between temperature and $\mathrm{RH}<100 \%$ was not tested, because initial experiments showed that the production of both pycnidia and cirri was already very low at $95 \% \mathrm{RH}$. The different RH levels were obtained by adding different volumes of glycerol to the PDA (Dallyn and Fox 1980), and the actual RH value was measured with an AquaLab LITE meter (version 1.3; Decagon Devices Inc., Pullman, WA). There were five replicate dishes per $\mathrm{RH}$ or temperature treatment. Every 1 or 2 days, the lesions were photographed with a digital camera until the 16th day after lesion appearance (DALA). Lesion area (in square centimeters) was determined, and numbers of pycnidia per square centimeter of lesion and numbers of pycnidia bearing cirri per square centimeter of lesion were determined with Assess 2.0 (Lamari 2008). The experiments were repeated once.

To determine the effect of temperature on conidia production, three replicate groups, each containing 50 cirri, were randomly collected with a needle from 10 lesions for each temperature regime at the end of experiment 2 (i.e., at 16 DALA). Cirri were placed in an Eppendorf tube with $0.5 \mathrm{ml}$ of sterile distilled water and were agitated with a vortex apparatus $(2,400 \mathrm{rpm})$ for $1 \mathrm{~min}$ to liberate the conidia. The number of conidia in three replicate drops of the suspension was determined with a hemocytometer and was expressed as the number of conidia per cirrus. The experiment was repeated once.

To determine the effect of the temperature at which conidia were produced on conidial germination, conidial suspensions obtained as described in the previous paragraph (from the temperature treat-

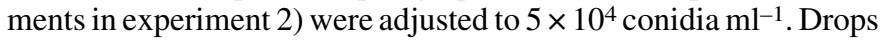
(10 $\mu \mathrm{l} / \mathrm{drop})$ of each conidial suspension were placed on plugs of WA ( $5 \mathrm{~mm}$ in diameter, 1 drop/plug), which had been placed on microscope slides ( 75 by $25 \mathrm{~mm}$ ); there were three microscope slides, each of them with three agar plugs (i.e., nine plugs per temperature treatment). Microscope slides were then incubated in darkness at $25^{\circ} \mathrm{C}$ and $100 \% \mathrm{RH}$. Germination was determined after $0,3,6,12,24$, and $48 \mathrm{~h}$ by examining 100 conidia on each agar plug with a microscope ( $\times 200$ magnification). Conidia were scored as germinated if the germ tube was longer than the diameter of the conidium. Germination was expressed as a percentage, and the experiment was repeated once.

Data analysis. A preliminary analysis of variance showed no significant differences between repeated experiments; therefore, the data were pooled.

The numbers of pycnidia per square centimeter of lesion in experiments 1 and 2 and the numbers of conidia produced in experiment 2 were rescaled by dividing each value by the maximum observed in the experiment (i.e., under optimal RH for experiment 1 and under optimal temperature for experiment 2). The rescaled values were used as response variables in nonlinear regression models. These models were compared based on the Akaike's Information Criterion (AIC), and the models providing the smallest AIC values were selected (Burnham and Anderson 2002).

The effect of time after lesion appearance and $\mathrm{RH}$ on pycnidia production (experiment 1) was best described by a modified Gompertz equation. In the general form of the Gompertz equation, $Y=\lambda \times \exp [-\alpha \times \exp (-\beta \times t)]$ (Madden et al. 2007), the three equation parameters describe the response variable $Y$ at any time $t$, with $\lambda$ being an estimate of the asymptotic (maximal) value, $\alpha$ the weighted mean relative growth rate, and $\beta$ the time at which maximum growth rate occurs (i.e., the point of inflection). In the modified equation (1) below, $\lambda=1$ because data were rescaled to the maximal value, and $\alpha$ and $\beta$ are linear functions of $\mathrm{RH}$, as follows:

$$
Y=e^{(-a \times R H+b) \times e^{-(c \times R H+d) \times D A L A}}
$$

where $Y$ is the rescaled number of pycnidia per square centimeter of lesion; DALA is the number of days after lesion appearance; and $a$, $b, c$, and $d$ are the equation parameters.

The effect of time after lesion appearance and temperature on production of pycnidia (experiment 2) was best described by a Weibull equation (Caffi et al. 2016; Carisse et al. 2000) in the following form:

$$
Y=A \times\left(1-e^{-f(T) \times(D A L A-C)^{D}}\right)
$$

where $Y$ is the rescaled number of pycnidia per square centimeter of lesion; DALA is the number of days after lesion appearance; $A, C$, and $D$ are the equation parameters; and $f(T)$ is a function describing the effect of temperature as:

$$
f(T)=E \times\left(\frac{H+1}{H} \times H^{\frac{1}{H+1}}\right) \times \frac{e^{(T-F) \times \frac{G}{H+1}}}{1+e^{(T-F) \times G}}
$$

where $T$ is temperature $\left({ }^{\circ} \mathrm{C}\right)$ and $E, F, G$, and $H$ are equation parameters.

The effect of each equation parameter on the shape of the response curve has been extensively explained by Duthie (1997). Briefly, $A(-\infty<A<+\infty)$ represents the upper limits of the response, 
$C(C>0)$ represents the lag period before the response to wetness, $D$ $(D>0)$ is the fraction of the wetness period in which the response decelerates, $E(E>0)$ represents the maximum response at the optimal temperature, $F(-\infty<F<+\infty)$ locates the curve on the horizontal axis as a function of the optimal temperature, $G(G>0)$ represents the intrinsic rate of increase in response to temperature, and $H(-\infty<H<+\infty)$ characterizes the asymmetry of the curve with respect to the optimal temperature. The optimal temperature is calculated by $T_{\mathrm{opt}}=F-(1 / \mathrm{G}) \times \ln (H)$. Because the response variable was rescaled from 0 to $1, A$ and $E$ were fixed to 1 (Duthie 1997).

The effect of temperature on production of conidia (experiment 2) was best described by a $\beta$ equation (Analytis 1977) in the following form:

$$
Y=a \times T e q^{b} \times(1-T e q)^{c}
$$

where $Y$ is the relative number of conidia; $a, b$, and $c$ are the equation parameters; and Teq is an equivalent of temperature, calculated as:

$$
T e q=\frac{T-T_{\min }}{T_{\max }-T_{\min }}
$$

where $T$ is the temperature regime, and $T_{\max }$ and $T_{\min }$ are maximum and minimum temperatures, respectively, at which pycnidia is able to produce conidia.

Goodness-of-fit of the equations was assessed based on the adjusted $R^{2}$, the magnitude of the standard error of the parameter estimates, the root mean square error (RMSE), the coefficient of residual mass (CRM), and the concordance correlation coefficient

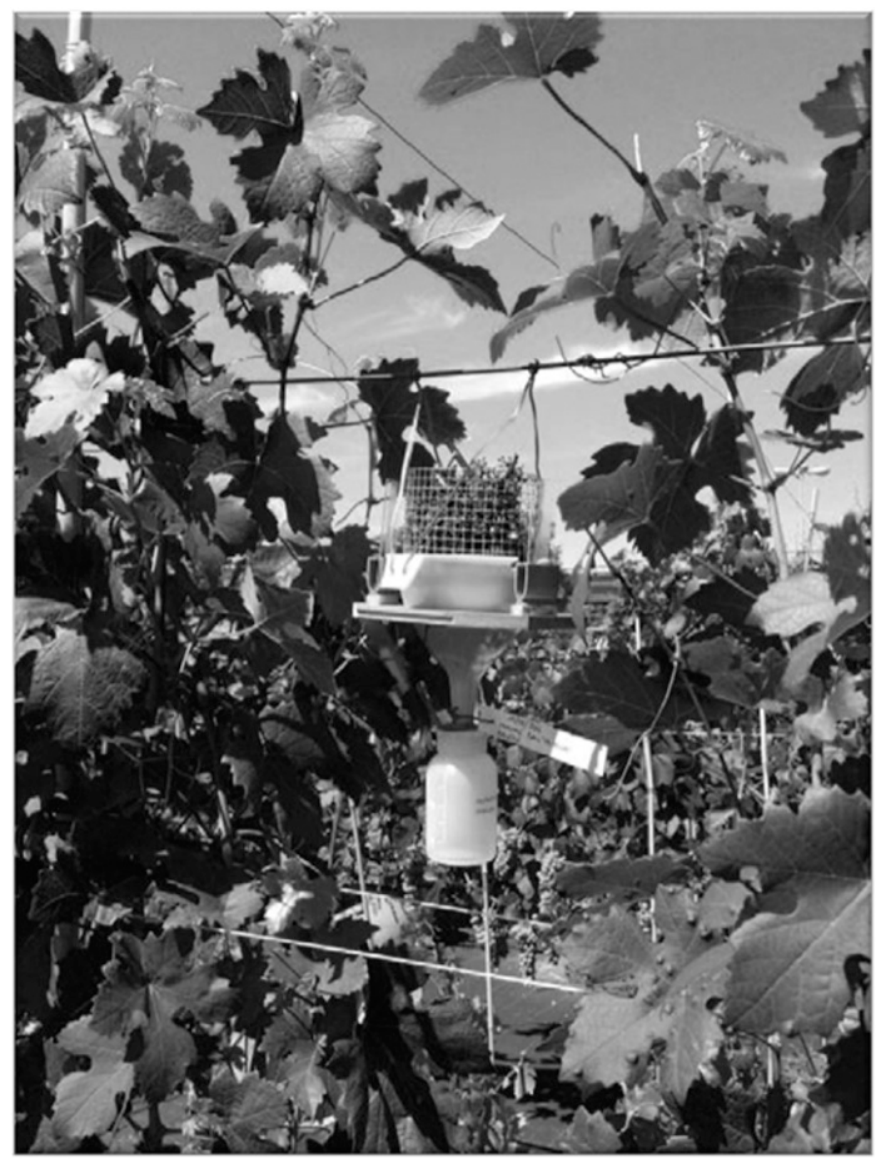

Fig. 1. Image of the containers with Guignardia bidwellii inoculum. Containers were made of metallic screen, with 90 -mm-wide openings. The inoculum consisted on $20 \mathrm{~g}$ of mummified black rot berries collected at the end of the previous growing season from commercial vineyard.
(CCC) (Lin 1989; Nash and Sutcliffe 1970). Briefly, RMSE represents the average distance of real data from the fitted line, and CRM is a measure of the tendency of the equation to overestimate or underestimate the observed values (a negative CRM indicates a tendency of the model to overestimate) (Nash and Sutcliffe 1970). $\mathrm{CCC}$ is the product of two terms: the Pearson correlation coefficient and the coefficient $\mathrm{Cb}$, which indicates the difference between the best fitting line and the perfect agreement line $(\mathrm{CCC}=1$ indicates perfect agreement) (Madden et al. 2007).

Field study. A 3-year field study (2013 to 2015) was carried out in a 7-year-old (in 2013) vineyard of Barbera grape at the University of Piacenza campus (northern Italy, $45^{\circ} 2^{\prime} \mathrm{N}, 19^{\circ} 43^{\prime} \mathrm{E}$ ). Plants were trained on a Guyot trellis system, and a single, 15 -m-long row was used. No fungicides were applied to the row or to any other part of the vineyard during the experiment. A standard weather station (Meteo Sense 2.0; Netsens s.r.l., Firenze, Italy) located in the vineyard provided hourly records of air temperature $\left({ }^{\circ} \mathrm{C}\right), \mathrm{RH}(\%)$, rainfall (in millimeters), and leaf wetness duration (in hours).

In late February of each year of the 3-year study, G. bidwellii inoculum was introduced into the experimental vineyard. The inoculum consisted of mummified black rot berries that had been collected at the end of the previous growing season from three to five commercial vineyards; these commercial vineyards were located in northern Italy and were severely affected with black rot. The collected mummies were kept outdoors during the winter. In the following February, the mummies were mixed to form one composite sample before a 20 -g subsample was placed in each of nine containers made of metallic screen with 90-mm-wide openings (Fig. 1). The containers were attached to the trellis of one vine row of 13 plants, and were $1.80 \mathrm{~m}$ above the ground and $1.5 \mathrm{~m}$ apart along the vine row. The mummies were left in position throughout the growing season.

In the row with berry mummies, all grape leaves were carefully observed every 2 or 3 days from bud break until berry ripening to

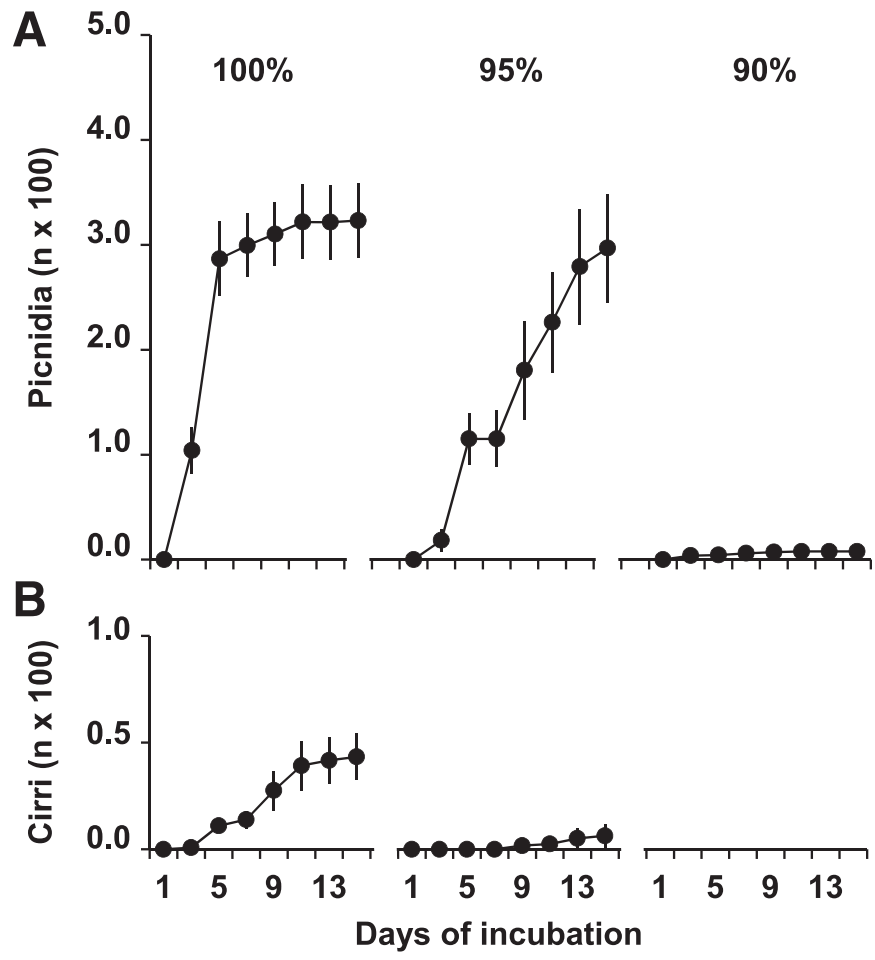

Fig. 2. Effect of relative humidity $(\mathrm{RH})$ on $\mathbf{A}$, cumulative numbers of pycnidia and $\mathbf{B}$, cumulative numbers of pycnidia with cirri per square centimeter of black rot lesion on grape leaves in the laboratory. No pycnidia were produced at 60 and $80 \%$ RH. Pycnidia were enumerated on lesions incubated at $25^{\circ} \mathrm{C}$ for 16 days. Each value represents the average ( \pm standard error) of two repeated experiments and five lesions per experiment. 
detect the (i) onset of black rot lesions and (ii) first pycnidia appearance on each lesion. Groups of lesions appearing on the same day were tagged with a permanent mark and considered as a coeval cohort of lesions (hereafter simply named "cohort"). Only the 50 cohorts in which all the lesions produced pycnidia were considered in this work, which represented $5.5 \%$ of the total cohorts formed. There were 12 cohorts in 2013 (formed between 20 May and 3 July on 178 black rot lesions), 19 in 2014 (formed between 14 May and 16 July on 194 lesions), and 19 in 2015 (formed between 9 May and 3 June on 274 lesions). In total, 646 lesions were considered.

Data analysis. For each of the 646 lesions, the number of days from lesion appearance to the production of first pycnidium on the lesion (DFLTP) was calculated.

To study the relationships between weather conditions and DFLTP under field conditions, the following variables were calculated between the day of appearance of a lesion cohort and the day when $50 \%$ of the lesions of the cohort had formed pycnidia (named DFLTP50): average temperature, average RH, numbers of hours with $\mathrm{RH}>80 \%$ or $\mathrm{RH}>90 \%$, numbers of wet hours, total rainfall, and number of days with rain $>0.2 \mathrm{~mm}$. Pearson, Spearman, and Kendall correlation coefficients $(r, \rho$, and $\tau$, respectively) were then calculated between paired observations of DFLTP50 and the above weather variables. The Spearman's and Kendall's rank correlation coefficients were calculated because (i) they are nonparametric correlation coefficients (i.e., they detect monotonic nonlinear associations between variables) and (ii) they limits an outlier to the value of its rank and, therefore, are less sensitive than the Pearson correlation coefficient to strong outliers in the tails of both samples (Quinn and Keough 2011). For the variables showing significant correlation, data were further analyzed by calculating averages and standard errors of DFLTP50 for discrete intervals of the considered variable; this was done for average temperature based on $3^{\circ} \mathrm{C}$ intervals.

\section{RESULTS}

In vitro experiments. Effect of $R H$ on production of pycnidia and cirri. Pycnidia were produced at RH values between 90 and $100 \%$ but not at 65 or $80 \%$ (Fig. 2A). The first pycnidia were produced at $2.0 \pm 0.3$ and 5.6 $\pm 0.6 \mathrm{DALA}$ at 100 and $95 \% \mathrm{RH}$, respectively. At $90 \% \mathrm{RH}$, pycnidia were produced in only $21.4 \%$ of the lesions and in low numbers $\left(<10\right.$ pycnidia $\mathrm{cm}^{-2}$ of lesion at 16 DALA). Approximately 300 pycnidia $\mathrm{cm}^{-2}$ of lesion were produced
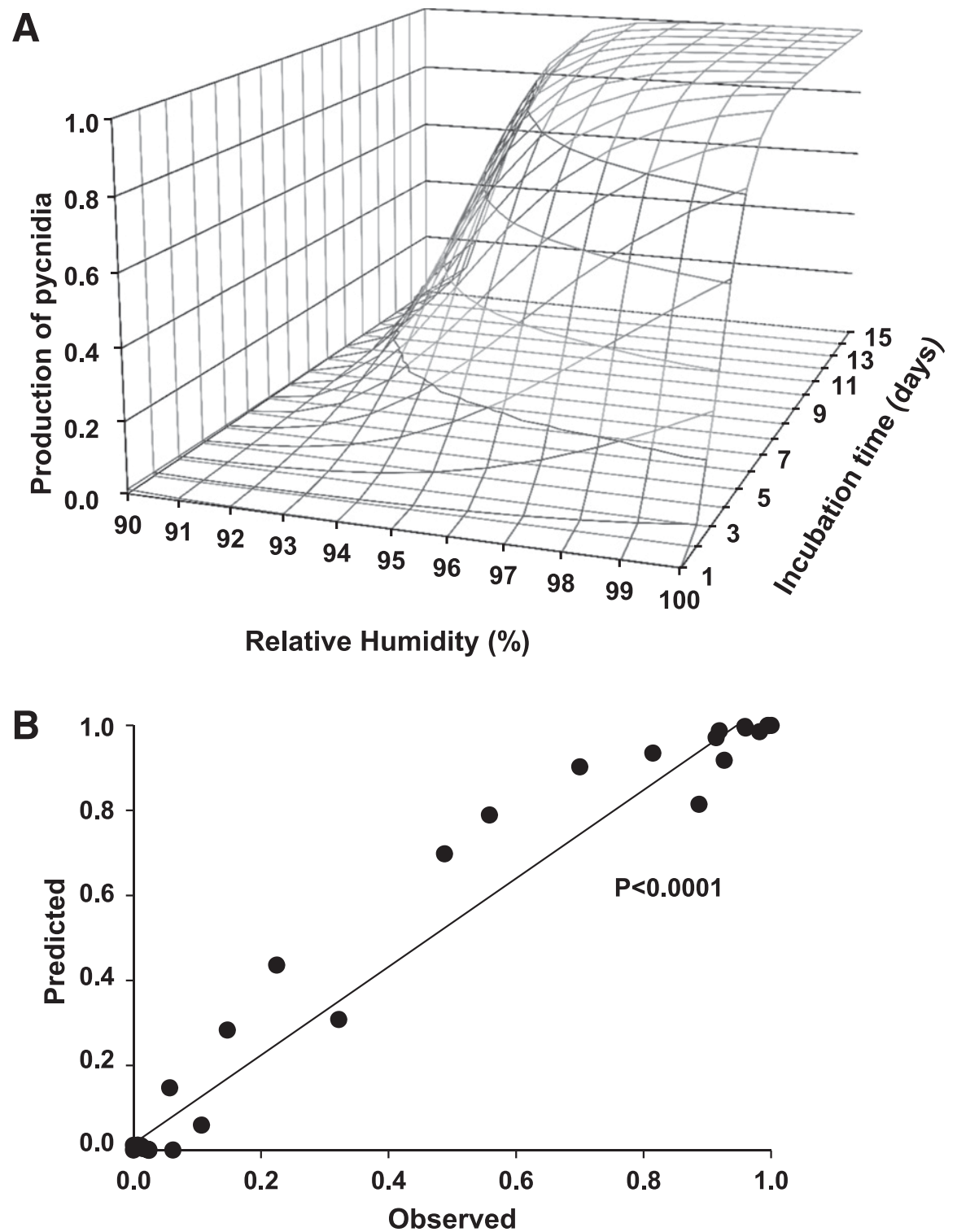

Fig. 3. Relationship between relative humidity, incubation time (in days), and rescaled production of Guignardia bidwellii pycnidia in grape leaf lesions in the laboratory, as predicted by equation 1 . A, Rescaled values were obtained by dividing each value by the maximum value at the optimal relative humidity. B, Comparison between observed and predicted production of pycnidia; $P$ value of the linear regression has been included. 
TABLE 1. Parameters, statistics, and goodness-of-fit indexes of the equations used to describe the effect of time and relative humidity (RH) (equation 1) or temperature (equation 2) on the cumulative number of Guignardia bidwellii pycnidia produced on black rot lesions in grape leaves, and the effect of temperature on production of conidia (equation 3$)^{\mathrm{a}}$

\begin{tabular}{cccccc}
\hline $\begin{array}{l}\text { Equation, } \\
\text { parameters }^{\mathrm{b}}\end{array}$ & Estimated parameters $^{\mathrm{c}}$ & $R^{2}$ & RMSE & CRM & CCC \\
\hline Eq. 1 & & 0.97 & 0.086 & -0.082 & 0.98 \\
$a$ & $1.25(0.26)$ & $\ldots$ & $\ldots$ & $\ldots$ & $\ldots$ \\
$b$ & $-109.4(24.2)$ & $\ldots$ & $\ldots$ & $\ldots$ & $\ldots$ \\
$c$ & $0.12(0.01)$ & $\ldots$ & $\ldots$ & $\ldots$ & $\ldots$ \\
$d$ & $-11.0(0.63)$ & $\ldots$ & $\ldots$ & $\ldots$ & $\ldots$ \\
Eq. 2 & & 0.95 & 0.087 & -0.049 & 0.97 \\
$C$ & $1.85(0.06)$ & $\ldots$ & $\ldots$ & $\ldots$ & $\ldots$ \\
$D$ & $0.74(0.05)$ & $\ldots$ & $\ldots$ & $\ldots$ & $\ldots$ \\
$F$ & $24.98(0.19)$ & $\ldots$ & $\ldots$ & $\ldots$ & $\ldots$ \\
$G$ & $0.48(0.02)$ & $\ldots$ & $\ldots$ & $\ldots$ & $\ldots$ \\
$H$ & $1.30(0.05)$ & $\ldots$ & $\ldots$ & $\ldots$ & $\ldots$ \\
Eq. 3 & & 0.98 & 0.042 & 0.011 & 0.99 \\
$a$ & $23.37(14.67)$ & $\ldots$ & $\ldots$ & $\ldots$ & $\ldots$ \\
$b$ & $1.42(0.31)$ & $\ldots$ & $\ldots$ & $\ldots$ & $\ldots$ \\
$c$ & $3.92(0.68)$ & $\ldots$ & $\ldots$ & $\ldots$ & $\ldots$ \\
\hline
\end{tabular}

a $R^{2}=$ coefficient of determination, $\mathrm{RMSE}=$ root mean square error, $\mathrm{CRM}=$ coefficient of residual mass, and $\mathrm{CCC}=$ concordance correlation coefficient.

b Equation 1 has the following formula: $Y=\exp [(-a \times \mathrm{RH}+b) \times \exp (-[c \times$ $\mathrm{RH}+d] \times \mathrm{DALA})]$, where $Y$ is the rescaled number of pycnidia per square centimeter of lesion; DALA is the number of days after lesion appearance; and $a, b, c$, and $d$ are the equation parameters. Equation 2 has the following formula: $Y=A \times\left[1-\exp \left(-f[T] \times[\text { DALA }-C]^{D}\right)\right]$, where $Y$ is the rescaled number of pycnidia per square centimeter of lesion; DALA is the number of days after lesion appearance; $A, C$, and $D$ are the equation parameters (with $A=1)$; and $f(T)$ is a function describing the effect of temperature as $f(T)=E \times$ $[(H+1) / H] \times\left[H^{\wedge}(1 / H+1)\right] \times[\exp ([T-f] \times g /[H+1]) /(1+\exp [(T-F) \times G])]$, where $T$ is temperature $\left({ }^{\circ} \mathrm{C}\right)$ and $E, F, G$, and $H$ are equation parameters (with $E=1)$. Equation 3 has the following formula: $Y=a \times \mathrm{Teq}^{b} \times(1-\mathrm{Teq})^{c}$, where $Y$ is the rescaled number of conidia; $a, b$, and $c$ are the equation parameters; and Teq is an equivalent of temperature calculated as Teq $=\left(T-T_{\min }\right) /\left(T_{\max }-\right.$ $\left.T_{\min }\right)$, where $T$ is the temperature regime, $T_{\min }=10^{\circ} \mathrm{C}$, and $T_{\max }=40^{\circ} \mathrm{C}$.

c Standard errors of the estimated parameters are in parentheses. by 16 DALA at both 95 and $100 \%$ RH but the production rate was greater at 100 than at $95 \%$ RH (Fig. 2A).

At $100 \% \mathrm{RH}$, pycnidia began extruding cirri at $4.6 \pm 0.4$ DALA, and 43.3 pycnidia $\mathrm{cm}^{-2}$ of lesion ( $13.4 \%$ of the pycnidia) had extruded cirri by 16 DALA (Fig. 2B). At $95 \%$ RH, extrusion of cirri began at $10.3 \pm 1.2$ DALA in a few lesions, and only 6.4 pycnidia $\mathrm{cm}^{-2}$ of lesion ( $2.14 \%$ of the pycnidia) had extruded cirri by 16 DALA. No cirri were extruded between 90 and 65\% RH (Fig. 2B).

Equation 1 provided a good fit of the rescaled cumulative number of pycnidia produced as a function of $\mathrm{RH}$ and time after lesion appearance (Fig. 3). The equation parameters had low standard errors compared with the parameter estimates, and the calculated indices indicated goodness-of-fit; negative CRM values indicated a slight overestimation (Table 1).

Effect of temperature on production of pycnidia and cirri. Pycnidia were produced at temperatures between 5 and $35^{\circ} \mathrm{C}$; no pycnidia were produced at $40^{\circ} \mathrm{C}$ within the 16 days of the experiment. The dynamic of pycnidia production and the numbers of the pycnidia produced were both influenced by temperature (Fig. 4A).

The time elapsed between the appearance of a black rot lesion and DFLTP decreased as temperature increased from 5 to $20^{\circ} \mathrm{C}$, was relatively similar between 20 and $30^{\circ} \mathrm{C}$, and slightly increased at $35^{\circ} \mathrm{C}$ (Fig. 5). For instance, the time required for $90 \%$ of the total pycnidia to be produced was approximately 13 days at $5^{\circ} \mathrm{C}, 5$ to 6 days at 20 to $30^{\circ} \mathrm{C}$, and 7 days at $35^{\circ} \mathrm{C}$ (Fig. 5). Between 5 and $15^{\circ} \mathrm{C}$, new pycnidia continued to be produced for the duration of the experiment (i.e., until 16 days) whereas, at $\geq 20^{\circ} \mathrm{C}$, pycnidia production reached a plateau after 5 to 7 days (Fig. 4A). The cumulative number of pycnidia produced increased as the temperature increased between 5 and $20^{\circ} \mathrm{C}$ and then decreased at 30 and $35^{\circ} \mathrm{C}$ (Fig. $4 \mathrm{~A}$ ).

Pycnidia did not extrude cirri at 5 or $10^{\circ} \mathrm{C}$, and only 1.1 and $5.5 \%$ of the pycnidia formed cirri at 15 or $35^{\circ} \mathrm{C}$, respectively; at 20,25 , and $30^{\circ} \mathrm{C}$, $10.9,23.5$, and $20.9 \%$ of the pycnidia, respectively, extruded cirri (Fig. 4B). At $25^{\circ} \mathrm{C}$, the first cirri were extruded after 3 days, and the cumulative number extruded progressively increased until 16 days (Fig. 4B).
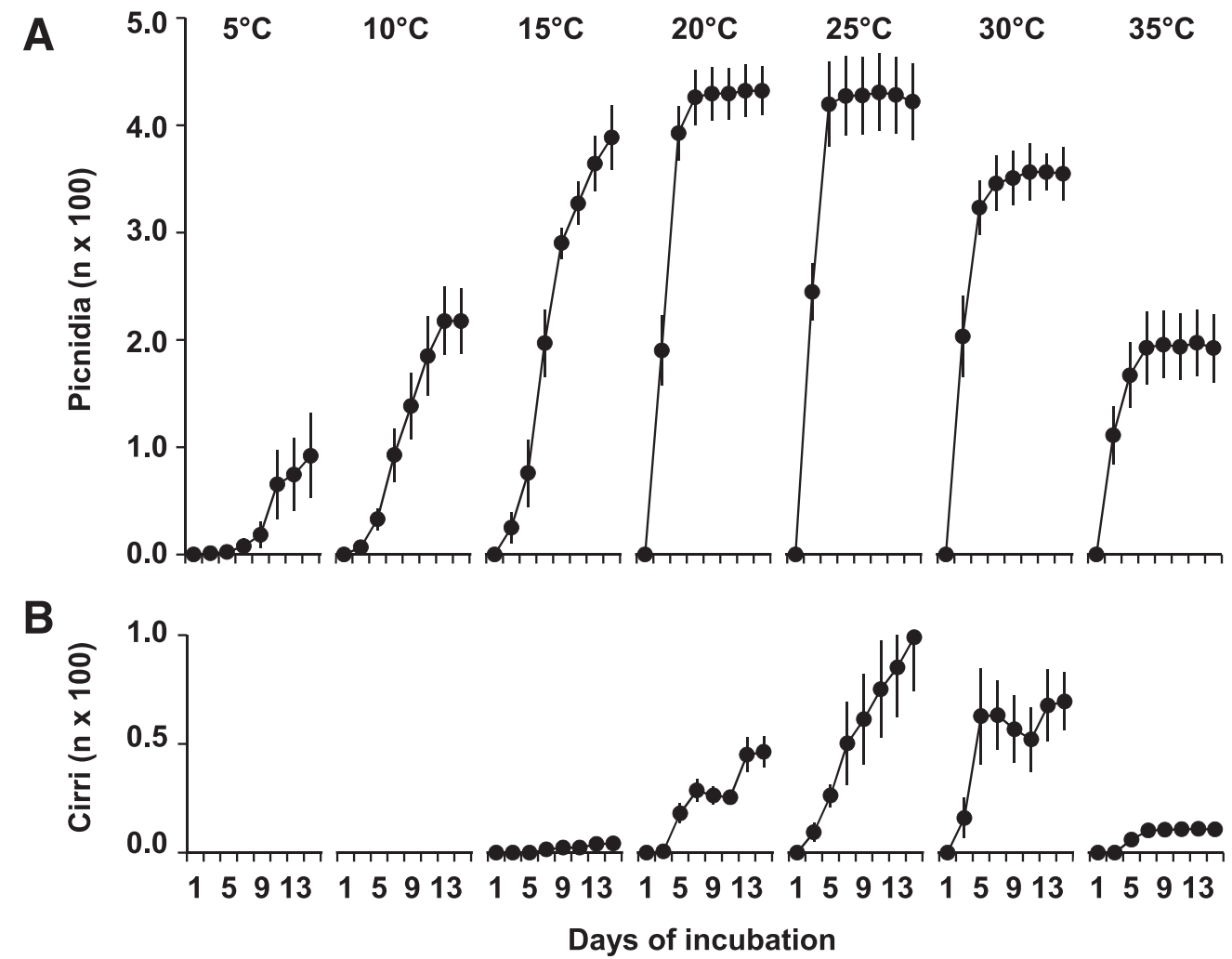

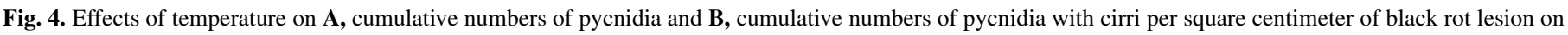

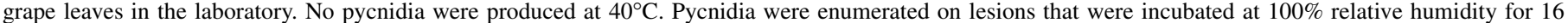
days. Each value represents the average ( \pm standard error) of two repeated experiments and five lesions per experiment. 


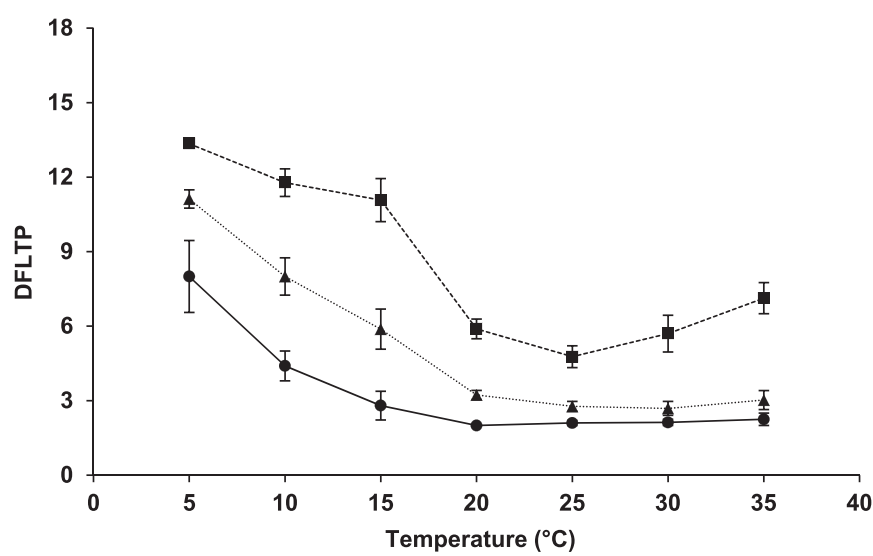

Fig. 5. Effect of temperature on the number of days between the appearance of a black rot lesion on grape leaves and the production of pycnidia on that lesion in the laboratory (DFLTP). Circles (solid line), triangles (dotted line), and squares (dashed line) indicate the DFLTP for the first pycnidia produced, for the first $50 \%$ of all pycnidia produced, and for the first $90 \%$ of all pycnidia produced, respectively. Each value represents the average ( \pm standard error) of two repeated experiments and five lesions per experiment. No pycnidia were produced at $40^{\circ} \mathrm{C}$.
Equation 2 provided a good fit of the rescaled cumulative number of pycnidia produced as a function of temperature and time after lesion appearance (Fig. 6). The equation parameters had low standard errors compared with the parameter estimates, RMSE values were low, and $R^{2}$ and CCC values were $\geq 0.95$; the CRM value was negative but very low (Table 1), indicating no substantial overestimation.

The estimate for parameter $c$ of the Weibull equation for pycnidia production was $1.85 \pm 0.06$, indicating a delay between lesion appearance and pycnidia appearance. The estimated optimal temperature was $24.43^{\circ} \mathrm{C}$ and parameter $h$ was $>1$, indicating a degree of asymmetry (i.e., the intrinsic rate of increase in the response up to the optimal temperature was higher than the rate of decline after this temperature) (Table 1; Fig. 6A).

Effect of temperature on production and germination of conidia. The number of conidia per cirrus was determined for cirri that formed at 15 to $35^{\circ} \mathrm{C}$ but not at 5,10 , or $40^{\circ} \mathrm{C}$ because no cirri formed at the latter three temperatures (Fig. 7). Equation 3 provided a good fit of the rescaled cumulative number of conidia produced as a function of temperature (Fig. 7). The calculated indices indicated goodness-of-fit; positive CRM value indicated a slight underestimation (Table 1).
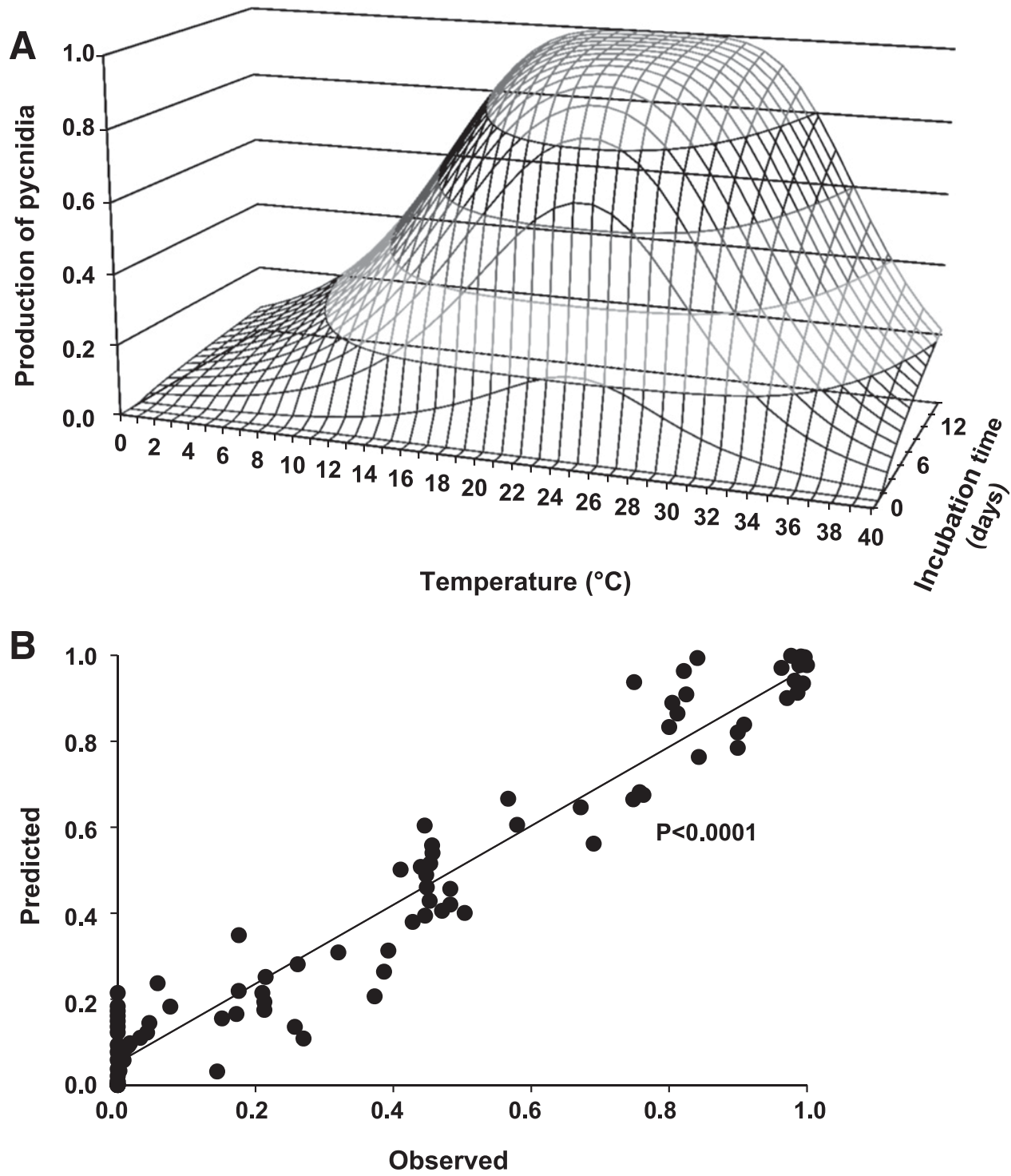

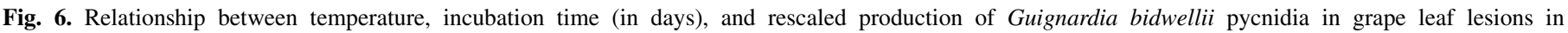

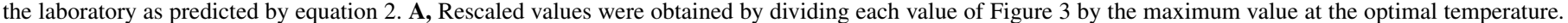
B, Comparison between observed and predicted production of pycnidia; $P$ value of the linear regression has been included. 
The number of conidia per cirrus was relatively high at 15 and $20^{\circ} \mathrm{C}$, progressively lower at 25 to $35^{\circ} \mathrm{C}$, and very low at $35^{\circ} \mathrm{C}$ (Fig. 7). Germination was similar for conidia produced at 20,25, and $30^{\circ} \mathrm{C}$ but was lower for conidia produced at $15^{\circ} \mathrm{C}$ (Fig. 8).

Field study. The cumulative numbers of lesions in a cohort that produced pycnidia in 2013 (12 cohorts), 2014 (19 cohorts), and 2015 (19 cohorts) are indicated in Figure 9A, C, and E, respectively; the corresponding weather conditions are shown in Figure 9B, D, and F. Note that, in Figure 9A, C, and E, each line begins on the left when a cohort of lesions first appeared, increases as the number of lesions bearing pycnidia in this cohort increases, and ends to the right when the last lesion in the cohort began to produce pycnidia. The frequency distribution of the DFLTP for the 646 lesions forming all 50 cohorts during the 3 years is shown in Figure 10.

The time for lesions to start producing pycnidia was highly variable. Approximately $22 \%$ of the lesions began to produce pycnidia within 2 days (Fig. 10); by 4 days, $56 \%$ of the lesions had begun to produce pycnidia. By 12 and 24 days, 87 and $91 \%$ of the lesions, respectively, had begun to produce pycnidia. Only $6 \%$ of the total lesions began to produce pycnidia between 19 and 24 days, and $<5 \%$ began to produce pycnidia between 35 and 40 days (Fig. 10).

The DFLTP was long for the cohorts formed in the last 10 days of May 2013 (Fig. 9A). Some lesions in these cohorts began producing pycnidia during a rainy and humid period in the last days of May (Fig. 9B). The number of lesions forming new pycnidia decreased in early June (which was dry) and increased again with rainfall on 9 June and the corresponding wet period. Some lesions in one of these cohorts began producing pycnidia when rain fell at the end of June. Other lesions with long DFLTP were observed for a cohort formed on 11 June 2014 (Fig. 9C). In this cohort, lesions began producing pycnidia on 16 June, after 3 days of rain (Fig. 9D). In the following dry period, only a few lesions produced their first pycnidia but most did produce their first pycnidia at the end of June, after a rainy period.

The relationship between rain and formation of pycnidia was confirmed for other lesion cohorts, such as those formed in early June 2014 (Fig. 9A and B), between late June and the first 10 days of July 2014 (Fig. 9C and D), and in May 2015 (Fig. 9E and F), but was not confirmed for all cohorts. For instance, lesions of the cohorts formed at the end of May 2015 produced pycnidia at 7 to 8 DALA (Fig. 9E) even though the weather was hot and mostly dry (Fig. 9F). The same occurred for the cohorts formed at the end of June 2015 (Fig. 9E and F).
As a consequence, no significant correlation was found between DFLTP50 and rainfall, RH, or leaf wetness in that period. A significant, negative correlation was found between DFLTP50 and average temperature $(r=-0.31, P=0.03 ; \rho=-0.45, P=0.001 ; \tau=$ $-0.337, P=0.001 ; n=50$ ) (i.e., DFLTP50 declined as average temperature increased) (Fig. 11). Higher values of Spearman and Kendall's correlation coefficients indicated a nonlinear relationship between temperature and DFLTP50 (Fig. 11).

\section{DISCUSSION}

To our knowledge, this is the first published study addressing the effect of time, temperature, and RH on both the production of pycnidia and the extrusion of cirri in G. bidwellii lesions on grape leaves.

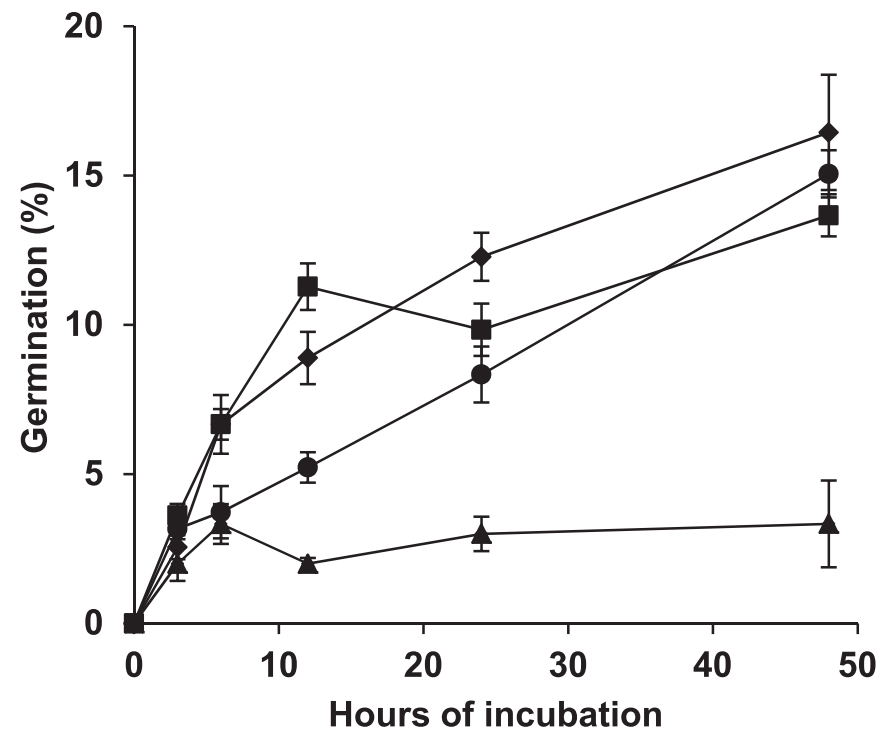

Fig. 8. Effect of the temperature at which Guignardia bidwellii pycnidia were produced in grape leaf lesions on the germination of conidia in the laboratory. Conidia were collected from cirri extruded from pycnidia in lesions that were kept for 16 days at $100 \%$ relative humidity and at $15(\boldsymbol{\Delta}), 20(\bullet), 25(\bullet)$, and $30^{\circ} \mathrm{C}(\boldsymbol{\square})$. No cirri were extruded at 5,10 , or $40^{\circ} \mathrm{C}$. Symbols indicate averages ( \pm standard error) of two experiments, and 100 conidia were assessed per experiment.

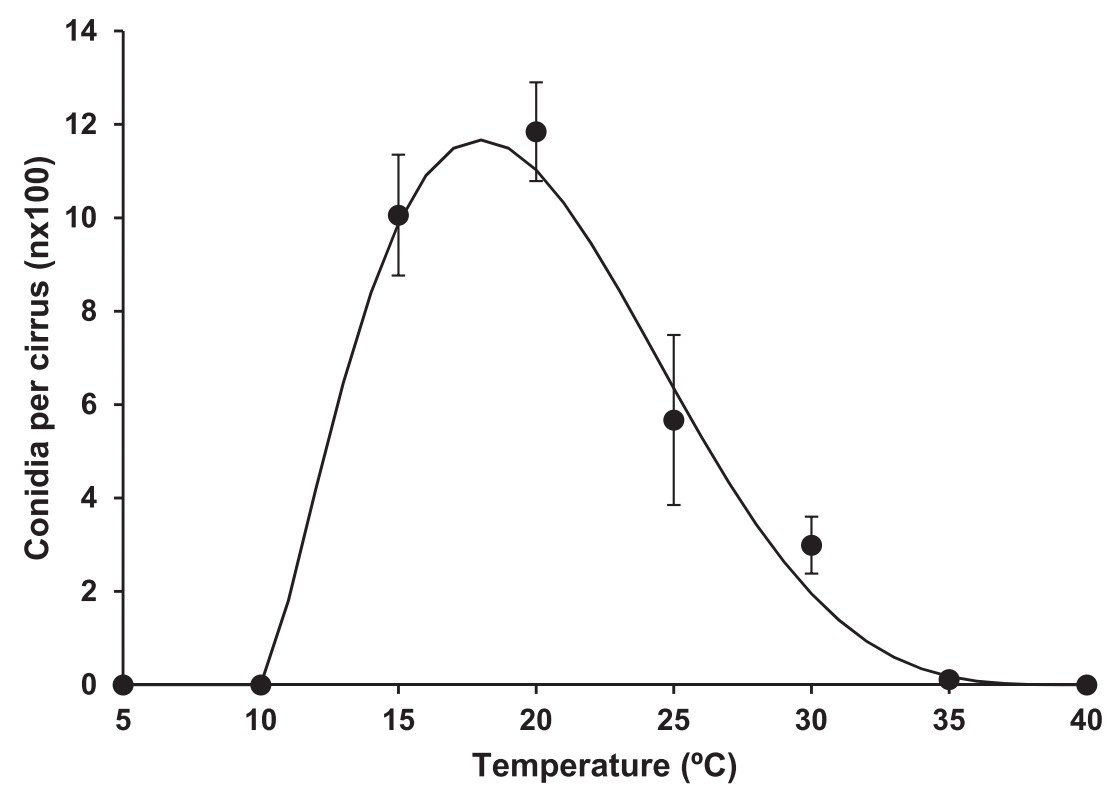

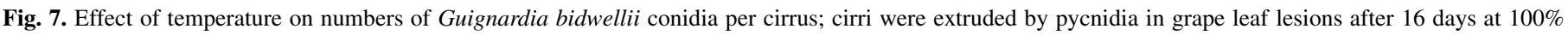

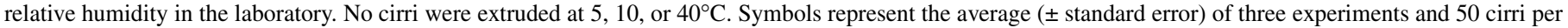
experiment. Line represents the relationship between temperature and number of conidia as described by equation 3 . 
Pycnidia of $G$. bidwellii were produced over a wide range of temperatures $\left(5\right.$ to $\left.35^{\circ} \mathrm{C}\right)$ and at 90 to $100 \% \mathrm{RH}$ but the numbers of pycnidia produced were highest between 20 and $30^{\circ} \mathrm{C}$. Consistent with these results, Caltrider (1961) and Spotts (1980) found that the optimal temperature for production of $G$. bidwellii pycnidia was $25^{\circ} \mathrm{C}$. Spotts (1980) found pycnidia in grape leaf lesions at all temperatures tested $\left(15,21\right.$, and $\left.26.5^{\circ} \mathrm{C}\right)$ but Caltrider $(1961)$ did not observe pycnidia at 10,15 , or $35^{\circ} \mathrm{C}$. The inconsistencies between
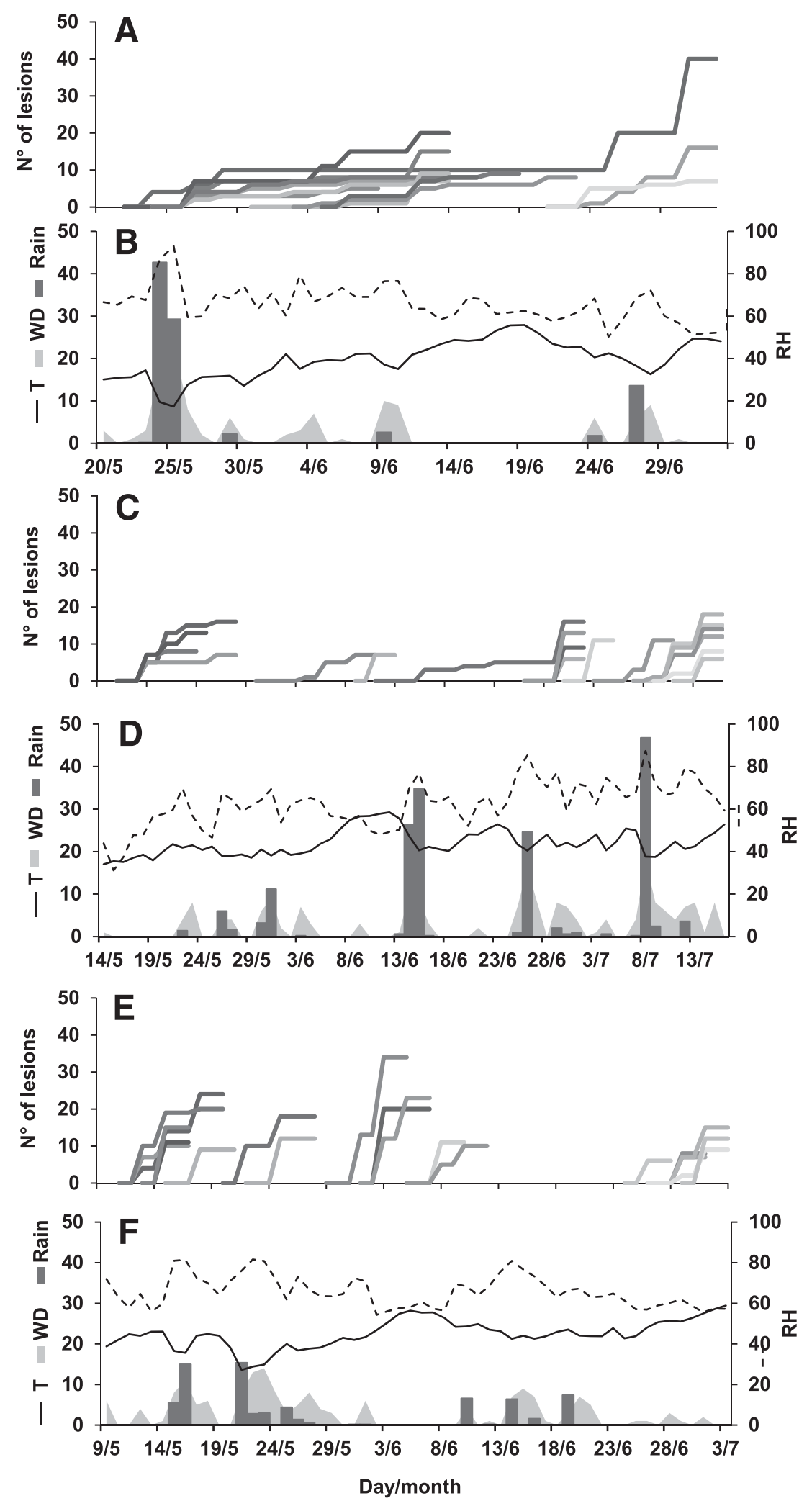

Fig. 9. Cumulative numbers of lesions in a cohort that completed the time intervals between appearance of Guignardia bidwellii lesions and appearance of pycnidia on those lesions as a function of date in a vineyard in A, 2013; C, 2014; and E, 2015. Each line begins on the left when a cohort of lesions first appeared, increases as the number of lesions bearing pycnidia in this cohort increases, and ends to the right when the last lesion in the cohort began to produce pycnidia. $\mathbf{B}, \mathbf{D}$, and $\mathbf{F}$, Corresponding weather data for these years: temperature $\left(\mathrm{T},{ }^{\circ} \mathrm{C}\right.$; solid line), relative humidity (RH, \%; dashed line), rainfall (Rain, mm; dark gray bars), and wetness duration (WD, hours; light gray area). Coeval cohorts of black rot lesions were observed every 2 to 3 days to determine the time when single lesions of each cohort began producing G. bidwellii pycnidia. 
results of the present study and those of Caltrider (1961) may be caused by differences in experimental conditions: Caltrider (1961) observed production of pycnidia in fungal colonies growing for 15 days in glucose-yeast-extract agar. Perhaps the 15-day-old colonies did not have sufficient time to produce pycnidia at suboptimal temperatures; in the current study, the rates at which pycnidia were produced were slower at these suboptimal temperatures than at optimal temperatures (Fig. 4). This is also the case for other fungi producing pycnidia. Stagonospora meliloti colonies growing on an artificial medium for 15 days produced pycnidia only within a narrow temperature range (i.e., 15 to $30^{\circ} \mathrm{C}$ ) (Erwin et al. 1987). However, $P$. viticola (Anco et al. 2013) infecting grape, $P$. amygdale (Lalancette et al. 2003) infecting peach, and Diaporthe citri (Mondal et al. 2007) infecting citrus produced pycnidia on host tissues over a wide range of temperature (from 1 to 5 to 35 to $38^{\circ} \mathrm{C}$ ).

The period from lesion appearance to pycnidia production on leaves was also influenced by temperature (i.e., the first pycnidia were produced in approximately 2 days after lesion appearance at $\geq 20^{\circ} \mathrm{C}$ and in 8 days after lesion appearance at $5^{\circ} \mathrm{C}$ ). These results agree with those of Spotts (1980) at 15 to $26.5^{\circ} \mathrm{C}$ but they extend the range of temperatures investigated. Pycnidia continued to be produced on the same lesion for 5 to 16 days after lesion appearance, depending on temperature (Fig. 4). That pycnidia are produced for several days on a leaf lesion and that the duration of pycnidia production is temperature dependent were also confirmed under fluctuating temperatures in our field study. In Septoria tritici, the time required for production of pycnidia in lesions on wheat leaves decreased as temperature increased from 5 to $20^{\circ} \mathrm{C}$ (Shaw 1990; Shearer and Zadoks 1972); in a field experiment, this period decreased by 3 days when the temperature increased from 10 to $16^{\circ} \mathrm{C}$ (Shaw 1990). In S. tritici, the spaced appearance of pycnidia in lesions can generate an apparently continuous epidemic from a single infection event (Rovle et al. 1986; Shaw 1990). Based on our results, the same may be true for G. bidwellii.

The temperature at which pycnidia were produced influenced the numbers of conidia produced per pycnidium as well as conidial germination. More conidia were produced in pycnidia that developed at 15 and $20^{\circ} \mathrm{C}$ than at 25,30 , or $35^{\circ} \mathrm{C}$. Considering that the optimal temperature for pycnidia production was between 20 and $25^{\circ} \mathrm{C}$, production of inoculum (reflecting the number of pycnidia per lesion and the number of conidia per pycnidium) was highest at $20^{\circ} \mathrm{C}$. For the fungi that produce pycnidia, P. amygdali (Lalancette et al. 2003) and P. viticola (Anco et al. 2013), favorable temperatures for production of conidia were 17 and $21^{\circ} \mathrm{C}$, respectively, and, therefore, were similar to those temperatures favoring conidia production by G. bidwellii.

The germination rates of G. bidwellii conidia were lower in the current study than in Caltrider (1961). The germination rates reported in the current study, however, were confirmed by assays conducted with conidia that were collected in our field study (data not shown).

G. bidwellii did not produce pycnidia on grape leaf lesions when the RH was maintained at $\leq 80 \%$. High RH is also required by other fungi that produce pycnidia; the minimum $\mathrm{RH}$ for pycnidia production was $86 \%$ for Didymella rabiei on chickpea (NavasCortés et al. 1998), 74\% for Diaporthe citri on citrus (Mondal et al. 2007), and $90 \%$ for S. nodorum on wheat (Shearer and Zadoks 1972). Spotts (1980) observed no differences in the time when pycnidial production began in black rot lesions on grape leaves for plants that were incubated in growth chambers at 90,70 , or $50 \% \mathrm{RH}$. Other than indicating " $\pm 10 \%$ RH” at any RH level, Spotts (1980) provided no information on the extent of the daily fluctuations in RH or on how RH was maintained in the growth chambers. It seems

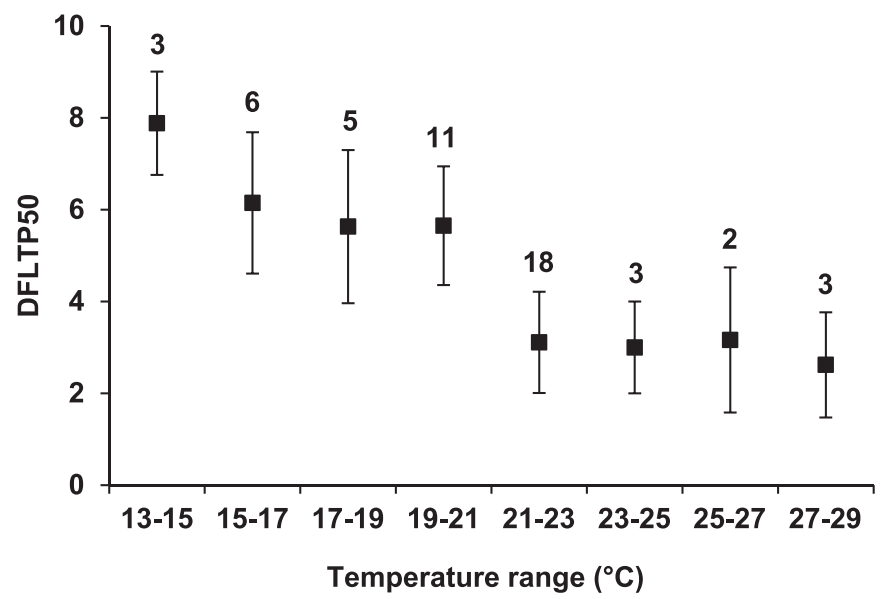

Fig. 11. Numbers of days elapsed between the appearance of a cohort of black rot lesions in grape leaves and the time when $50 \%$ of the cohort had formed pycnidia (DFLTP50) as related to temperature. Symbols indicate averages ( \pm standard error), and the number above each symbol is the number of cohorts for the indicated temperature range. Data were derived from the 50 cohorts described in Figure 9.

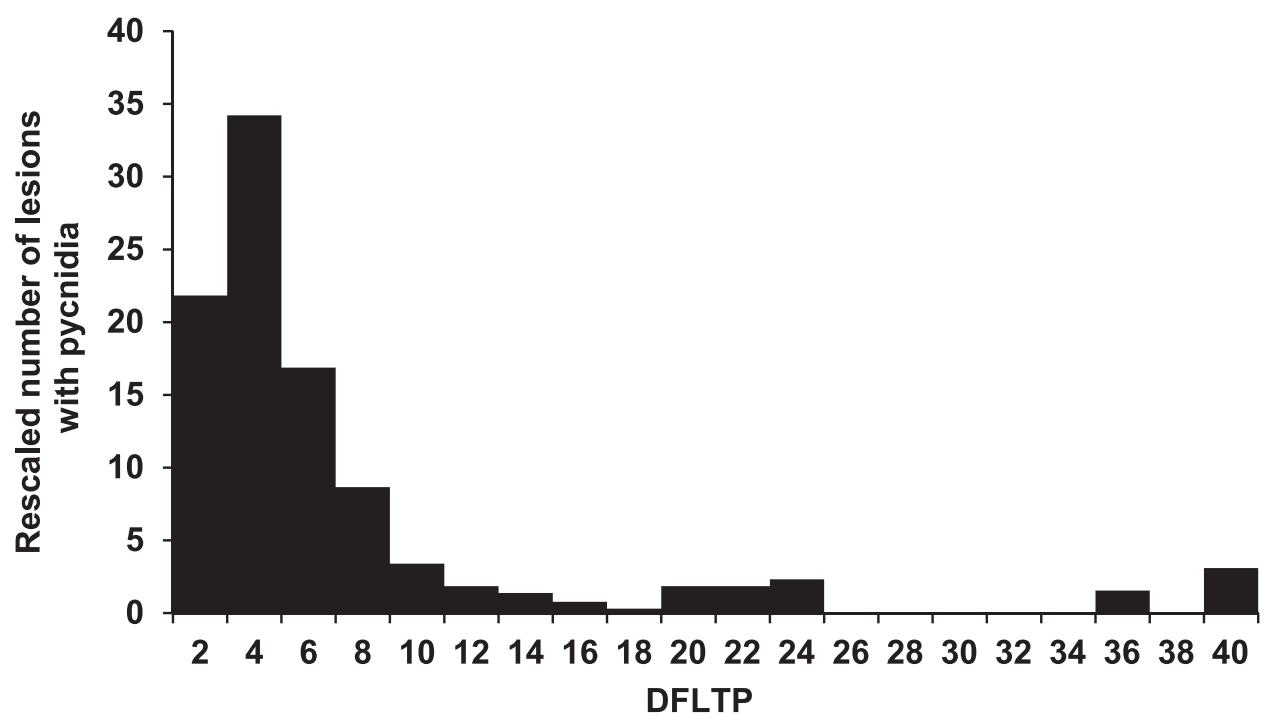

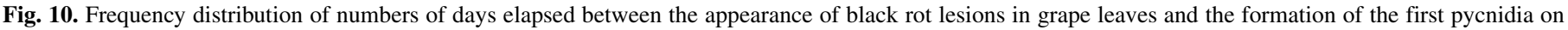
those lesions (DFLTP) for the 646 lesions observed in the vineyard in 2013, 2014, and 2015. Lesions are those shown in Figure 9. 
likely that, during the period between lesion appearance and the appearance of the first pycnidium (a period of approximately 4 days), the RH in the growth chambers used by Spotts reached a suitable RH for enough hours to support pycnidia production; based on the results of the current work, the suitable RH would be $>80 \%$. This hypothesis is supported by the research of Navas-Cortés et al. (1998) on Didymella rabiei and that of Shearer and Zadoks (1972) on $S$. nodorum. D. rabiei failed to produce pycnidia at $\mathrm{RH}<87 \%$; when lesions were incubated at 100 and $34 \% \mathrm{RH}$ at alternating weekly intervals, production of pycnidia was similar to that found under continuous moist conditions (Navas-Cortés et al. 1998). $S$. nodorum failed to produce pycnidia at $\mathrm{RH}<90 \%$ but produced similar numbers of pycnidia with a continuous $100 \% \mathrm{RH}$ and with alternating 12 -h periods at 80 and $100 \%$ RH (Shearer and Zadoks 1972).

In the current field study, a clear relationship was not detected between rainfall or humidity and (i) the production of pycnidia on leaf lesions and (ii) the time between lesion appearance and pycnidial development. Overall, the findings from the present work showed that production of conidia requires high humidity (no pycnidia were produced at constant low humidities) but that some hours at high humidity rather than constant high humidity may be sufficient.

Cirri were extruded only between 15 and $35^{\circ} \mathrm{C}$ (the optimum was $25^{\circ} \mathrm{C}$ ) and mainly at $100 \% \mathrm{RH}$; however, only a small percentage of the pycnidia extruded cirri in the laboratory experiment. That the extrusion of cirri from pycnidia requires water is well known; Janex-Favre et al. (1993), for example, observed that mature pycnidia formed cirri some minutes after the deposition of a film of water.

The discrepancy between the number of pycnidia produced and those able to extrude a cirrus can be explained by the presence or absence of water and by pycnidial ontogeny. Pycnidia development in G. bidwellii involves several stages, which include the formation of a primordial within a stroma and the development of a fertile center that produces a conidiogenous layer covering the pycnidial cavity; the pycnidial neck can form either before or after the development of the fertile center. The conidia and the ostiole in the pycnidial neck appear after (Janex-Favre et al. 1993). Therefore, pycnidia are visible before they contain mature conidia, and such pycnidia cannot extrude a cirrus until the conidia are mature.

In a recent analysis of the literature, Rossi et al. (2014) described the dynamics of pycnidial production on leaf lesions as a main gap in our understanding of black rot of grape. In the absence of this information, Rossi and colleagues used the results from previous works on both G. bidwellii and other fungi that produce pycnidia to model the life cycle. The present work represents important improvements compared with previous ones (Caltrider 1961; Spotts 1980; Viala and Pacottet 1904). The wider range of temperatures and incubation periods considered for pycnidia production ( 5 to $35^{\circ} \mathrm{C}$ and 1 to 16 days) and the additional evaluation of both production and extrusion of conidia increase our current understanding of the biology and epidemiology of G. bidwellii. Moreover, accurate equations were developed in this work to account for the effect of temperature and $\mathrm{RH}$ on the production of secondary inoculum by G. bidwellii. These results can contribute to better disease management because berry infections are mainly caused by secondary inoculum (Carisse et al. 2009; Ramsdell and Milholland 1988).

The results of this work can also be incorporated in the model developed by Rossi et al. (2014); the mechanistic approach used to develop the model will facilitate this incorporation (De Wolf and Isard 2007; Rossi et al. 2010). More specifically, the nonlinear equations developed to describe the production of pycnidia as affected by time, RH (with a modified Gompertz equation), and temperature (with a Weibull equation) can be used to estimate the inoculum potential for secondary infections. Both equations have parameters with relevant biological meaning (Duthie 1997; Madden et al. 2007) and have been previously used for other plant pathogens
(Anco et al. 2013; Arauz et al. 2010; González-Domínguez et al. 2013).

In conclusion, this work increases our knowledge on the biology and epidemiology of G. bidwellii and specifically on (i) formation of pycnidia and cirri in grape leaf lesions, (ii) production and germination of conidia, and (iii) length of the period between lesion appearance and pycnidia production. The results showed that environmental conditions for pycnidia production were less restrictive than for cirri extrusion. Pycnidia were produced in a wide range of temperatures and with $\mathrm{RH} \geq 90 \%$ but cirri were extruded only between 15 and $35^{\circ} \mathrm{C}$ and mainly at $100 \% \mathrm{RH}$. The production of pycnidia in the same lesion continued for at least 16 days. These results were used to develop new equations describing the production patterns of pycnidia on leaf lesions that can now be incorporated in a mechanistic model previously developed by Rossi et al. (2014).

\section{ACKNOWLEDGMENTS}

G. Onesti carried out this work within the Doctoral School on the AgroFood System (Agrisystem) of the Università Cattolica del Sacro Cuore (Italy).

\section{LITERATURE CITED}

Analytis, S. 1977. On the relation between biological development and temperature of some plant pathogenic fungi. Phytopathol. Z. 90:64-76.

Anco, D. J., Madden, L. V., and Ellis, M. A. 2013. Effects of temperature and wetness duration on the sporulation rate of Phomopsis viticola on infected grape canes. Plant Dis. 97:579-589.

Arauz, L. F., Neufeld, K. N., Lloyd, A. L., and Ojiambo, P. S. 2010. Quantitative models for germination and infection of Pseudoperonospora cubensis in response to temperature and duration of leaf wetness. Phytopathology 100:959-967.

Burnham, K. P., and Anderson, D. 2002. Model Selection and Multimodel Inference: A Practical Information-Theoretic Approach, 2nd ed. Springer, New York.

Caffi, T., Legler, S. E., Gonzalez-Dominguez, E., and Rossi, V. 2016. Effect of temperature and wetness duration on infection by Plasmopara viticola and on post-inoculation efficacy of copper. Eur. J. Plant Pathol. 144: 737-750.

Caltrider, P. 1961. Growth and sporulation of Guignardia bidwellii. Phytopathology 51:860-863.

Carisse, O., Bacon, R., Lasnier, J., Lefebvre, A., Levasseur, A., Rolland, D., and Jobin, T. 2009. Grape disease management in Quebec. AAFC number 10372. Agriculture and Agri-Food Canada, Quebec, Canada.

Carisse, O., Bourgeois, G., and Duthie, J. A. 2000. Influence of temperature and leaf wetness duration on infection of strawberry leaves by Mycosphaerella fragariae. Phytopathology 90:1120-1125.

Dallyn, H., and Fox, A. 1980. Spoilage of material of reduced water activity by xerophilic fungi. Pages 129-139 in: Microbial Growth and Survival in Extremes of Environment. J. E. L. Gould and G. H. Corry, eds. Academic Press, London, UK.

De Wolf, E. D., and Isard, S. A. 2007. Disease cycle approach to plant disease prediction. Annu. Rev. Phytopathol. 45:203-220.

Duthie, J. A. 1997. Models of the response of foliar parasites to the combined effects of temperature and duration of wetness. Phytopathology 87:1088-1095.

Ellis, M. A., Madden, L. V., and Wilson, L. L. 1986. Electronic grape black-rot predictor for scheduling fungicides with curative activity. Plant Dis. 70: 938-940.

Erwin, D., Khan, R., Ribeiro, O., and Lehman, W. 1987. Growth, sporulation, and pathogenicity of Stagonospora meliloti and selection for resistance to crown rot and leaf spot in alfalfa. Plant Dis. 71:181-185.

Ferrin, D. M., and Ramsdell, D. C. 1977. Ascospore dispersal and infection of grapes by Guignardia bidwellii, the causal agent of grape black-rot disease. Phytopathology 67:1501-1505.

Ferrin, D. M., and Ramsdell, D. C. 1978. Influence of conidia dispersal and environment on infection of grape by Guignardia bidwellii. Phytopathology 68:892-895

González-Domínguez, E., Rossi, V., Armengol, J., and García-Jiménez, J. 2013. Effect of environmental factors on mycelial growth and conidial germination of Fusicladium eriobotryae, and the infection of loquat leaves. Plant Dis. 97:1331-1338.

Hoffman, L. E., Wilcox, W. F., Gadoury, D. M., and Seem, R. C. 2002. Influence of grape berry age on susceptibility to Guignardia bidwellii and its incubation period length. Phytopathology 92:1068-1076. 
Hoffman, L. E., Wilcox, W. F., Gadoury, D. M., Seem, R. C., and Riegel, D. G. 2004. Integrated control of grape black-rot: Influence of host phenology, inoculum availability, sanitation, and spray timing. Phytopathology 94: 641-650.

Janex-Favre, M. C., Parguey-Leduc, A., and Jailloux, F. 1993. The ontogeny of pycnidia of Guignardia bidwellii in culture. Mycol. Res. 97:1333-1339.

Jhorar, O. P., Butler, D. R., and Mathauda, S. S. 1998. Effects of leaf wetness duration, relative humidity, light and dark on infection and sporulation by Didymella rabiei. Plant Pathol. 47:586-594.

Kuo, K., and Hoch, H. C. 1996. The parasitic relationship between Phyllosticta ampelicida and Vitis vinifera. Mycologia 88:626-634.

Lalancette, N., Foster, K. A., and Robison, D. M. 2003. Quantitative models for describing temperature and moisture effects on sporulation of Phomopsis amygdali on peach. Phytopathology 93:1165-1172.

Lamari, L. 2008. Assess 2.0: Image Analysis Software for Plant Disease Quantification. American Phytopathological Society Press, St. Paul, MN.

Lin, L. 1989. A concordance correlation coefficient to evaluate reproducibility. Biometrics 45:255-268.

Madden, L. V., Hughes, G., and van den Bosch, F. 2007. The Study of Plant Disease Epidemics. American Phytopathological Society Press, St. Paul, MN.

Magarey, R. D., Coffey, B. E., and Emmett, R. W. 1993. Anthracnose of grapevines, a review. Plant Prot. Q. 8:106-110.

Molitor, D., and Beyer, M. 2014. Epidemiology, identification and disease management of grape black rot and potentially useful metabolites of black rot pathogens for industrial applications - a review. Ann. Appl. Biol. 165: 305-317.

Molitor, D., Fruehauf, C., Baus, O., and Berkelmann-Loehnertz, B. 2012. A cumulative degree-day-based model to calculate the duration of the incubation period of Guignardia bidwellii. Plant Dis. 96:1054-1059.

Mondal, S. N., Vicent, A., Reis, R. F., and Timmer, L. W. 2007. Saprophytic colonization of citrus twigs by Diaporthe citri and factors affecting pycnidial production and conidial survival. Plant Dis. 91:387-392.

Nash, J., and Sutcliffe, J. 1970. River flow forecasting through conceptual models part I. J. Hydrol. 10:282-290.

Navas-Cortés, J. A., Trapero-Casas, A., and Jimenez-Diaz, R. 1998. Influence of relative humidity and temperature on development of Didymella rabiei on chickpea debris. Plant Pathol. 47:57-66.

Northover, P. 2008. Factors influencing the infection of cultivated grape (Vitis spp. section Euvitis) shoot tissue by Guignardia bidwellii (Ellis) Viala \& Ravaz. Ph.D. thesis, Pennsylvania State University Pennsylvania.

Quinn, G. P., and Keough, M. J. 2011. Experimental Design and Data Analysis for Biologists. 11th ed. Cambridge University Press, Cambridge, MA.
Ramsdell, D. C., and Milholland, R. 1988. Black-rot. Pages 15-17 in: Compendium of Grape Diseases. R. Pearson and A. Goheen, eds. American Phytopathological Society Press, St. Paul, MN.

Reddick, D. 1911. The black-rot disease of grapes. Cornell Univ. Agric. Exp. Stn. Bull. 293:289-364.

Rinaldi, P., Skaventzou, M., Rossi, M., Comparini, C., Sofia, J., Molitor, D., and Mugnai L. 2013 Guignardia bidwellii: Epidemiology and symptoms development in Mediterranean environment. J. Plant Pathol. 95:S1.83-S1.84.

Rossi, V., Giosuè, S., and Caffi, T. 2010. Modelling plant diseases for decision making in crop protection. Pages 241-258 in: Precision Crop Protection-The Challenge and Use of Heterogeneity. E.-C. Oerke, R. Gerhards, G. Menz, and R. A. Sikora, eds. Springer Netherlands, Dordrecht, The Netherlands.

Rossi, V., Onesti, G., Legler, S. E., and Caffi, T. 2014. Use of systems analysis to develop plant disease models based on literature data: Grape black-rot as a case-study. Eur. J. Plant Pathol. 141:427-444.

Rovle, D. J., Shaw, M. W., and Cook, R. J. 1986. Patterns of development of Septoria nodorum and in some winter wheat crops in Western Europe, 1981-1983. Plant Pathol. 35:466-476.

Rubboli, V., Ortugno, C., Coatti, C., and Gualco, A. 2014. Dynali, nuovo fungicida a base di cyflufenamid e difenoconazolo per la protezione della vite da oidio e black-rot. G. Fitopatol. 2:289-298.

Shaw, M. 1990. Effects of temperature, leaf wetness and cultivar on the latent period of Mycosphaerella graminicola on winter wheat. Plant Pathol. 39: 255-268.

Shearer, B., and Zadoks, J. 1972. The latent period of Septoria nodorum in wheat I. The effect of temperature and moisture treatments under controlled conditions. Eur. J. Plant Pathol. 78:231-241.

Sosnowski, M. R., Emmett, R. W., Wilcox, W. F., and Wicks, T. J. 2012. Eradication of black-rot (Guignardia bidwellii) from grapevines by drastic pruning. Plant Pathol. 61:1093-1102.

Spotts, R. A. 1980. Infection of grape by Guignardia bidwellii-factors affecting lesion development, conidial dispersal, and conidial populations on leaves. Phytopathology 70:252-255.

Vanniasingham, V., and Gilligan, C. 1989. Effects of host, pathogen and environmental factors on latent period and production of pycnidia of Leptosphaeria maculans on oil-seed rape leaves in controlled environments. Mycol. Res. 93:167-174.

Viala, P., and Pacottet, P. 1904. Recherches sue les maldies de la vigne: "Black-rot II, Sur le développment du Black-rot", réceptivité des fruits, influence de la temperature, de l'humidité et des milieux toxique. Bordeaux de la "Revue de viticulture", Paris. 